\title{
EXTRAVASCULAR DOPPLER MEASUREMENT OF CARDIAC OUTPUT IN INFANTS AND CHILDREN AFTER OPERATIONS FOR CONGENITAL HEART DISEASE
}

Laurance L. Lequier, MD, ${ }^{\mathrm{a}}$ Steven R. Leonard, MD, ${ }^{\mathrm{b}}$ Hisashi Nikaidoh, MD, ${ }^{\mathrm{b}}$ Matthew S. Lemler, MD, ${ }^{\mathrm{a}}$ and Claudio Ramaciotti, MD, ${ }^{\text {a }}$ Dallas, Tex

Cardiac output is a primary indicator of the effectiveness of the heart as a pump and is an important factor after operations for congenital heart disease. Methods for direct measurement

From the Department of Pediatrics, ${ }^{\text {a }}$ The University of Texas Southwestern Medical Center, and the Division of Pediatric Cardiothoracic Surgery, ${ }^{b}$ Children's Medical Center of Dallas, Dallas, Tex

Received for publication Dec 4, 1998; accepted for publication Jan $11,1999$. of cardiac output are limited, however, particularly in neonates. Echocardiography is noninvasive and readily available, but it is labor intensive and does not provide continuous

Address for reprints: Claudio Ramaciotti, MD, Children's Medical Center of Dallas, Department of Cardiology, 1935 Motor St, Dallas, TX 75235.

J Thorac Cardiovasc Surg 1999;117:1223-5

Copyright $\odot 1999$ by Mosby, Inc.

$0022-5223 / 99 \$ 8.00+0 \quad \mathbf{1 2 / 5 4 / 9 7 0 5 4}$ 


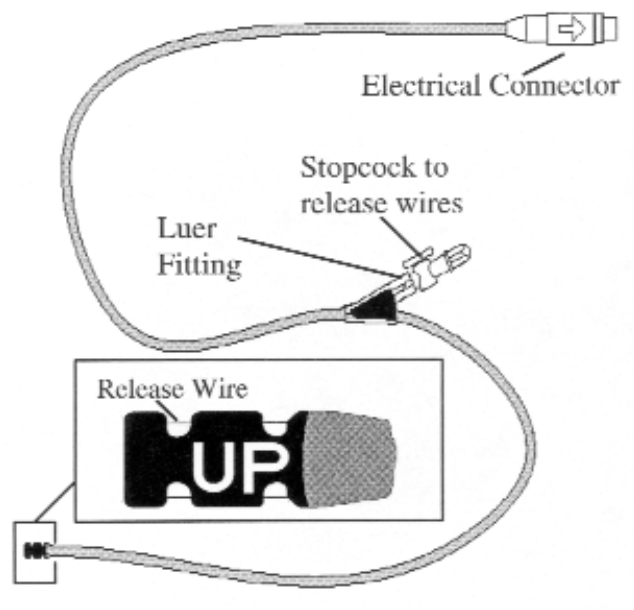

A

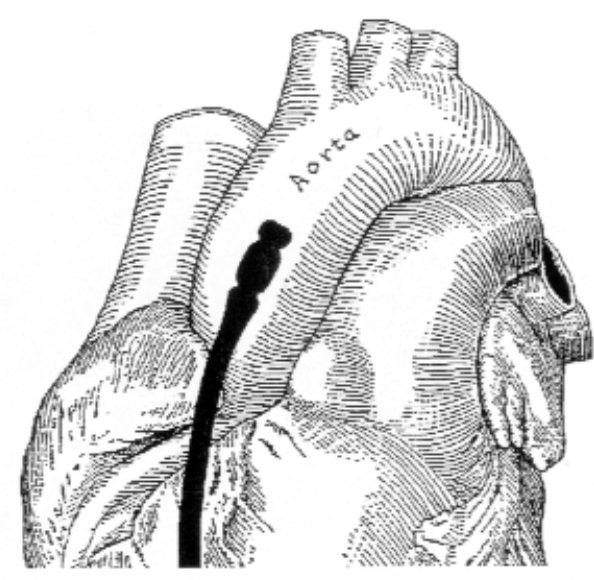

B

Fig 1. Extravascular Doppler probe. A, Probe head with thin wires for attachment, Luer-style wing nut mechanism, and electrical connection to ABCOM 2000 monitor are shown. B, Placement of extravascular Doppler probe on ascending aorta, 1 to $2 \mathrm{~cm}$ above aortic valve.

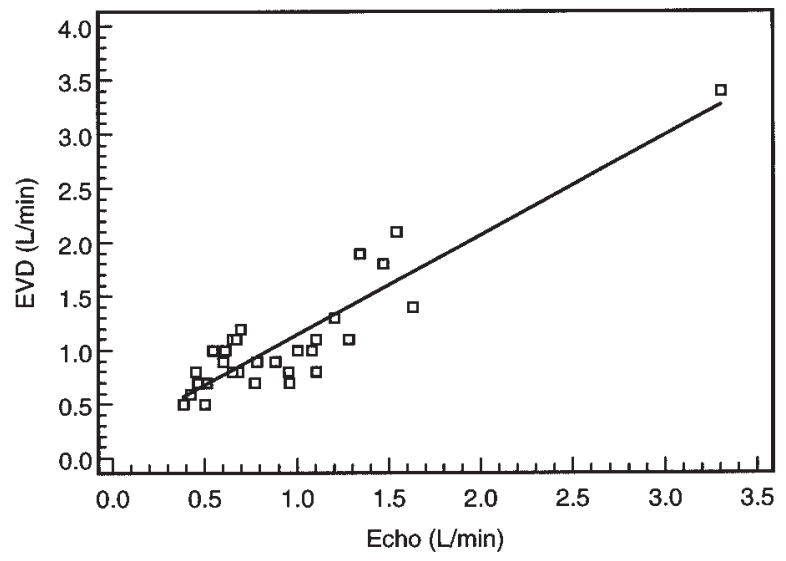

Fig 2. Simple regression analyses of cardiac output by extravascular Doppler (EVD) probe and by echocardiograpy (Echo). For 30 data points, $r=0.906$ (95\% confidence interval 0.81-0.95).

measurements of cardiac output. Pulmonary artery catheterization with thermodilution is an accepted method of measuring cardiac output, but it is not possible to obtain continuous assessment in infants and young children, and there are welldescribed limitations and complications associated with its use. ${ }^{1}$ There is always a small error in calculation of cardiac output by the direct oxygen Fick technique because of the presence of the bronchial circulation. This error is magnified if there is any residual shunt within the heart or between the great arteries. Extravascular Doppler probes sewn to the adventitia of the aorta have been shown to provide accurate cardiac output measurements during surgery when compared with thermodilution measurements in both adult human and animal studies. ${ }^{2,3}$ The validity of this measuring device has not previously been tested for infants and children, however, nor has it been tested in the postoperative setting.

Methods. We prospectively studied 11 children after cardiac operations for correction of congenital heart disease. The study was approved by the Institutional Review Board of The University of Texas Southwestern Medical Center and Children's Medical Center of Dallas. Cardiac output was continuously monitored with an extravascular Doppler probe (Applied Biometrics, Inc, Burnsville, Minn) and an ABCOM 2000 cardiac output monitor (Applied Biometrics). The $5 \times$ $10-\mathrm{mm}$ head of the probe was sutured with fine Prolene sutures (Ethicon, Inc, Somerville, NJ) to the adventitia of the ascending aorta 1 to $2 \mathrm{~cm}$ above the level of the aortic valve (Fig 1). The sutures were placed around thin retractable wires on either side of the probe head that passed through the probe cable and were attached to a wing nut mechanism. The cable was brought out through the skin by way of a small incision and subcutaneous tunnel. Rotation of the wing nut caused the wires to retract into the cable, releasing the probe from the sutures and allowing the probe to be removed percutaneously. The internal aortic diameter used for calculation of the cardiac output was estimated by subtracting $2 \mathrm{~mm}$ from the actual external diameter of the ascending aorta. An average of 3 echocardiographic determinations of cardiac output were obtained per patient within 48 hours of admission to the pediatric intensive care unit after the operation. The cardiac output determined with the extravascular Doppler probe was recorded immediately before echocardiographic calculation of cardiac output. Stroke volume was calculated echocardiographically as the product of cross-sectional area multiplied by the velocity time integral. The cross-sectional area of the left ven- 
tricular outflow tract was calculated from the measured diameter at the plane of the aortic valve. ${ }^{4}$ Aortic valve diameter was measured with the parasternal long-axis view. The aortic valve was assumed to be circular. Measurements were obtained in early systole at the level of the aortic valve leaflets.

Results. The median age of the patients enrolled was 4 months (range 2 weeks -4.5 years) and their median weight was $4.7 \mathrm{~kg}$ (range 2.8-17.1 kg). Six patients underwent ventricular septal defect repair, 2 patients underwent atrioventricular septal defect repair, and 1 patient each underwent total anomalous pulmonary venous return repair, tetralogy of Fallot repair, and a Rastelli procedure. A simple regression plot of extravascular Doppler-derived cardiac output against that obtained by echocardiography had an $r$ value of 0.906 (Fig 2). A Bland-Altman test of agreement was done and revealed the mean difference in cardiac index between the 2 methods to be $0.45 \mathrm{~L} \cdot \mathrm{min}^{-1} \cdot \mathrm{m}^{-2}$. No complications of bleeding or infection were noted in association with the use of the extravascular Doppler probes, nor were there any complications when the probes were removed transcutaneously at the end of the study period.

Discussion. In response to the limitations of thermodilution, echocardiography, and the direct oxygen Fick technique, we validated the use of an extravascular Doppler probe as an alternate method for measurement of cardiac output in children after correction of congenital heart disease. Although Doppler echocardiography is not a "standard" technique for measurement of cardiac output, it has been well validated. ${ }^{5}$ The results obtained with the 2 methods showed good correlation, with an $r$ value of 0.906 on simple regression analyses. The Bland-Altman test of agreement revealed a mean difference of $0.45 \mathrm{~L} \cdot \mathrm{min}^{-1} \cdot \mathrm{m}^{-2}$ between the 2 techniques. This is clinically acceptable in light of the wide range of cardiac output in our population of patients and because the trend in cardiac output is more important to follow than is the absolute value. We did not compare the extravascular Doppler probe with thermodilution because we considered the latter procedure too invasive for our population. We could not do Fick calculations of cardiac output because of either the presence of residual shunt or the lack of a cuffed endotracheal tube.

The continuous extravascular Doppler probe-derived cardiac output determinations accorded well with patient clinical assessments and therapeutic interventions. Increases in cardiac output were seen with volume infusions, increased inotropic support, and the addition of afterload reduction. Falls in cardiac output were noted during a pulmonary artery hypertensive crisis in 1 patient and with a pericardial effusion (before any other clinical indicators of this condition were seen) in another. Decreases in cardiac output were noted before blood pressure changes and before the development of decreased peripheral perfusion and urinary output. The extravascular Doppler probe even confirmed the adequacy of external chest compression during cardiopulmonary resuscitation. The extravascular Doppler probe was easy to implant, exited the chest through an individual stab wound similar to a thoracostomy tube, was easy to remove, and was not associated with bleeding, infection, or other complications.

The extravascular Doppler probe measurements of cardiac output were found to be valid and reliable in a population of patients of various ages and weights when compared with a previously validated measure of cardiac output. The extravascular Doppler probe was noninvasive to the vascular system and provided continuous measurement of cardiac output in patients undergoing cardiac operations, both in the operating room and throughout the postoperative recovery period. It correlated well with a patient's clinical condition, often indicating a change in cardiac output before other clinical parameters, and thus allowed more timely intervention.

\section{REFERENCES}

1. Kelso LA. Complications associated with pulmonary artery catheterization. N Horizons 1997;5:259-63.

2. Armstrong PJ, Campanelli C. Continuous cardiac output monitoring using the extravascular Doppler probe [abstract]. Fifth Meeting of The European Anaesthesia Research Group. European Academy of Anesthesiology, August 27, 1992.

3. Peterson RJ, Kissoon N, Murphy SP, Goodwin SR, Bayne EJ, Kelley EW, et al. Comparison of transtracheal and extravascular Doppler determinations of stroke volume and cardiac output at various states of volume loading in piglets. Crit Care Med 1995;23:2015-22.

4. Snider AR, Serwer GA, Ritter SB. Methods for obtaining quantitative information from the echocardiographic examination. In: Echocardiography in pediatric heart disease. 2nd ed. St Louis: Mosby-Year Book; 1997. p. 190-5.

5. Coats AJ. Doppler ultrasonic measurement of cardiac output: reproducibility and validation. Eur Heart J 1990;11(suppl):49-61. 